\title{
Topical Corticosteroid Misuse Among Females Attending a Dermatology Outpatient Department in Ethiopia
}

\author{
${ }^{*}$ Corresponding author \\ Feleke Tilahun Zewdu, MSc \\ Department of Tropical Dermatology \\ Boru Meda Hospital \\ Dessie, Ethiopia \\ Tel. +251-945107616 \\ E-mail: momflk@gmail.com
}

\section{Volume 2 : Issue 2}

Article Ref. \#: 1000TCOJ1108

\section{Article History \\ Received: May $3^{\text {rd }}, 2017$ \\ Accepted: May $30^{\text {th }}, 2017$ \\ Published: May $30^{\text {th }}, 2017$}

\section{Citation}

Zewdu FT, Abdulkerim A, Nigatu MD, Akenaw GM, Alemayehu MM. Topical corticosteroid misuse among females attending a dermatology outpatient department in Ethiopia. Trichol Cosmetol Open J. 2017; 2(2): 13-16. doi: 10.17140/TCOJ-2-108

\section{Copyright}

(C2017 Zewdu FT. This is an open access article distributed under the Creative Commons Attribution 4.0 International License (CC BY 4.0), which permits unrestricted use, distribution, and reproduction in any medium, provided the original work is properly cited.

\section{Feleke Tilahun Zewdu, MSc $^{1 *}$; Awel Abdulkerim, MSc $^{2}$; Mahelet Dessie Nigatu, BSc ${ }^{3}$; Getasew Mulatu Akenaw, MSc ${ }^{4}$; Mastewal Misganaw Alemayehu, BSc, MSc ${ }^{5}$}

\author{
${ }^{1}$ Department of Tropical Dermatology, Boru Meda Hospital, Dessie, Ethiopia \\ ${ }^{2}$ Department of Tropical Dermatology, Ayder Referral Hospital, Mekelle, Ethiopia \\ ${ }^{3}$ Department of Public Health Officer, Debretabore University, Debretabore, Ethiopia \\ ${ }^{4}$ Department of Emergency Medicine and Critical Care, Mekele University, Tigray, Ethiopia \\ ${ }^{5}$ Bahir Dar University, Bahirdar, Ethiopia
}

\section{ABSTRACT}

Introduction: Irrational use of topical corticosteroid (TC) is quite common in Ethiopia due to the unrestricted availability and use of topical steroids (TS) not only by general public but also by physicians and chemists. This practice is highly prevalent and sought after, owing to the quick relief of symptoms in different dermatological conditions and its nature of enhancing beauty for a certain period.

Objective: This study aims to evaluate and analyze the prevalence of misuse of topical steroids, causes behind the misuse and consequences after the use of topical steroids among females in a dermatology outpatient department (OPD) at Ayder Referral Hospital, Ethiopia.

Materials and Methods: A cross-sectional observational questionnaire based study was conducted from April to August 2015. Patients were questioned and assessed for misuse of topical steroids in terms of indication, dose, frequency, duration, effects after use and source of recommendation of topical steroids among female clients.

Results: During the study period, $104(27.1 \%)$ patients presented with inappropriate use of topical steroids among patients $(n=384)$ who were attended the OPD of dermatology unit at Ayder Referral Hospital, the only hospital providing treatment, care and preventive measures for dermatological cases, with a response rate of $97 \%$. A total of 72 patients were presented with adverse effects of topical steroids resulting from the misuse of these drugs for various purposes. Misuse of topical steroids was found to be most prevalent in the age group of 21-30 years $(51.15 \%)$ followed by age group between $11-20$ years $(21.15 \%)$, who were severely affected due to its inappropriate use. Whereas, melasma $(40.38 \%)$ and rosacea $(35.6 \%)$ were the most common reasons of steroid abuse, followed by facial acne $(26 \%)$, use as sunscreen 44 (42.3\%), non-specific dermatosis $35(33.7 \%)$ and skin lightening (10.58\%). Patients using topical corticosteroids as over-the-counter (OTC) after recommendation made by friends and family $(44.8 \%)$ was found to be a factor of influence on the misuse of topical steroids followed by pharmacist and drug store vendors as over the counter patterns of use $(31.7 \%)$. The least were recommended by clinicians $(10.57 \%$ ) for the treatment of acne, melasma/hyper-pigmentation and to improve the appearance during weddings and other ceremonies. Dermovate and dermalar $(70.18 \%)$ were the most commonly used topical steroid preparations, causing the patients to often develop fungal infections such as tinea incognito $(26.4 \%)$, followed by facial acne $(25.6 \%)$, telangiectasia and rosacea $(41 \%)$ being the most common side effects experienced.

Conclusion: Misuse of topical steroids was found to be very common owing to prescriptions by dermatologists, the major reason being recommendations by healthcare professionals, pharmacists, family and friends. Abuse of these steroids causes fungal, bacterial infections and rosacea which leads to many other secondary complications.

KEY WORDS: Topical steroid (TS); Misuse; Side effects female; Ayder. 
ABBREVIATIONS: TC: Topical Corticosteroid; TS: Topical Steroids; OPD: Outpatient department; OTC: Over-the-counter.

\section{INTRODUCTION}

The development of super potent corticosteroid in 1974 added more cutaneous diseases to the list of topical steroids (TS) indications. Meanwhile, TS misuse also appeared as a common problem adding a new complication which has been reported by variety of investigators. Thus, patients were subjected to become light skin, facial redness, facial hyper pigment and social out casted and loss of confidence after use of TS. ${ }^{1}$ Topical steroids play an important role in the wide spectrum of dermatological conditions especially those characterized by hyper proliferation, inflammation and immunological responses. ${ }^{2}$ TS are amongst the most commonly used medication in the outpatient Department of Dermatology because of its profound efficacy than the other group of drugs on the different skin conditions. ${ }^{3}$

Over the years TS is being increasingly abused by both patients and doctors as well. Apart from common indications such as psoriasis, atopic dermatitis, vitiligo, lichen planus, lichen simplex chronicus, discoid lupus erythematosus, etc., they are also being used for conditions such as melasma, urticaria, undiagnosed skin rashes by dermatologists and more so by general physicians. ${ }^{4}$ This is because of the quick symptomatic relief of many skin disorders by the application of TS in the first instance rather than dependence on physicians or specialists, i.e., dermatologist. In addition, to this, studies done in patients presenting with steroid-related side effects have shown that, there is an influence non-medical advisers like friends, neighbors, beauticians, barbers, etc., who encourage the use of TS as fairness/ cosmetic creams, anti-acne, anti-fungal therapy and for any skin eruptions. ${ }^{1}$

Friends and relatives sharing the same prescription presuming that similar looking skin problems can be self-treated by simply copying the old prescription is quite pervasive. Furthermore, there is unrestricted availability of these drugs at the chemist shops where pharmacists and quacks dispense TS without a valid prescription. Although, reported from many places worldwide, these instances have significant impact in countries like Ethiopia, with just a couple of dermatologists to serve a large population and no strict regulations on over-the-counter (OTC) prescription of these drugs. Because of the easy availability and affordable prices of these potent types of TCs, misuse has been noted among the general population, producing many undesirable effects. ${ }^{3,5}$

Chronic misuse of TS on the face produces a clinical condition described by various names, like light sensitive seborrheid, ${ }^{1}$ perioral dermatitis, ${ }^{6}$ rosacea-like dermatitis, ${ }^{7}$ steroid rosacea ${ }^{8}$ steroid dermatitis resembling rosacea,${ }^{9}$ and steroid-induced rosacea-like dermatitis. ${ }^{7}$

\section{Materials and Methods}

This observational cross-sectional study involved a total of 384 patients who attended Ayder Referral Hospital in Mekelle University in Ethiopia from April to August 2015. The study was approved by the Mekelle University Ethical Committee. The study included patients irrespective of age and indication. Past history of use of steroids was assessed on the basis of any records available with the patients and the medicines or prescriptions the patients carried. This also included the patients who complained of side effects of these drugs. Patients not willing to participate in the study and those on oral corticosteroids were excluded. All the patients included in the study were assessed for misuse of TS, defined as inappropriate use of topical steroid on skin in terms of incorrect dosing, formulation, frequency, duration or indications used for certain skin problems. This study was based on a self-designed questionnaire and the patients were examined for cutaneous adverse effects of TS. Patients were interviewed directly using pretested and structured questionnaire after getting their written informed consent.

Following this, patients were also counseled for the rational use of the topical steroid and appropriate treatment was given for the presence of side effects.

\section{RESULTS}

During the study period, 104 (27.1\%) patients presented with inappropriate use of topical steroids among patients $(n=384)$ who were attended the outpatient department (OPD) of dermatology unit at Ayder Referral Hospital, ekelle, Ethiopia, the only hospital providing treatment, care and preventive measures for dermatological cases, with a response rate of $97 \%$. Among these, $72(69.23 \%)$ patients were presented with various patterns of adverse side effects resulting from the misuse of topical steroids for various purposes.

More than half of the females with steroidal induced side effects were occur among age group between 11-30 years,

\begin{tabular}{|cc|}
\hline \multicolumn{2}{|c|}{ Table 1: Distribution of Age amongst Patients using Topical Steroids. } \\
\hline Age distribution (years) & Number of patients (\%) \\
\hline $11-20$ & $22(21.15 \%)$ \\
\hline $21-30$ & $52(51.15 \%)$ \\
\hline $31-40$ & $17(16.35 \%)$ \\
\hline $41-50$ & $9(8.7 \%)$ \\
\hline $51-60$ & $4(3.8 \%)$ \\
\hline
\end{tabular}


$74(72.3 \%)$ and followed by $31-40$ years, 17 (16.35\%) (Table 1).

The study were conducted among females patients $(n=384)$. Among these study subjects, 104 (27.1\%) of the subjects were used one or/and more topical steroids having various strength, 72 (69.23\%) of them having had one or more side effects on their faces.

Besides, 37 (35.6\%) of the total number of patients were recommended to use topical steroids by relatives, $33(31.7 \%)$ by private pharmacy owners, followed by $29(27.88 \%)$ by beauticians (Table 2).

Nearly third quarter, 72 (70.18\%) females were recommended to use betnovate and dermalar from private pharmacies and drug vendors followed by fairness creams from cosmetic centers and stores. Moreover, these agents were used combining two or more topical agents daily for an average period of 43 days. In addition, $79(76 \%)$ of them used cosmetics like yellow
Vaseline, scrubs and other fairness products guaranteeing to act as natural skin lighteners, sunscreen and anti-melasma ("madiate").

Nearly half of the females used topical steroids for the treatment of melasma $(40.38 \%)$, whereas the rest used them as sun screen $(42.3 \%)$ and to treat resacea $(35.6 \%)$. Even in other non-specific skin dermatosis cases, many patients (33.7\%) were reportedly using topical steroids for an average period of 2-6 months for various reasons and forms ranging from fairness products to dermovate (Table 3 ).

Moreover, $58.7 \%$ females complained of burning or itching sensations, $63.7 \%$ developed melasma and perioral dermatitis, $35.6 \%$ had diffuse facial redness, $28.8 \%$ steroidal acne, $26.9 \%$ resacea and $10.6 \%$ dry facial skin. Similarly, $42 \%$ of the females used these topical agents during day time, for an extended period of time after application (Table 4).

\begin{tabular}{|cc|}
\hline \multicolumn{2}{|c|}{ Table 2: Source of Recommendation for Topical Steroids Use. } \\
\hline Source of recommendation & Number of patients (\%) \\
\hline Beautician & $29(27.88 \%)$ \\
\hline Self-prescription & $17(16.34 \%)$ \\
\hline Pharmacy & $33(31.7 \%)$ \\
\hline Dermatologist & $11(10.57 \%)$ \\
\hline Relatives & $37(35.6 \%)$ \\
\hline Friends & $20(19.2 \%)$ \\
\hline
\end{tabular}

\begin{tabular}{cc}
\hline \multicolumn{2}{|c}{ Table 3: Type of Topical Steroids Used by the Patients. } \\
\hline Type of topical steroid used & Number of patients (\%) \\
\hline Dermalar & $31(29.8 \%)$ \\
\hline Betnovate & $42(40.38 \%)$ \\
\hline Betamethasone valerate & $5(4.8 \%)$ \\
\hline Fairnesscosmetics & $33(31.7 \%)$ \\
\hline More than one (above) & $47(45.1 \%)$ \\
\hline Others (scrub, yellow vaseline) & $79(76 \%)$ \\
\hline
\end{tabular}

\begin{tabular}{|cccc|}
\hline \multicolumn{3}{l}{ Table 4: Purpose and Effects of Steroids before and after Use. } \\
\hline \multicolumn{2}{c}{ Before use (Used for treating ) } & \multicolumn{2}{c}{ After use (Adverse effects) } \\
\hline Purpose & Number of patients $(\%)$ & Clinical findings & Number of patients (\%) \\
\hline Melasma & $42(40.38 \%)$ & Tinea incognito & $51(49 \%)$ \\
\hline Rosacea & $37(35.6 \%)$ & Melasma and POD & $64(63.7 \%)$ \\
\hline Fairness & $11(10.58)$ & Diffuse facial redness & $37(35.6 \%)$ \\
\hline Acne & $27(26 \%)$ & Dry facial skin & $11(10.6 \%)$ \\
\hline As sunscreen & $44(42.3 \%)$ & Rosacea & $28(26.9 \%)$ \\
\hline Non-specific dermatosis & $35(33.7 \%)$ & Burning or itching & $61(58.7 \%)$ \\
\cline { 2 - 4 } & & Steroidal acne & $30(28.8 \%)$ \\
\hline
\end{tabular}




\section{DISCUSSION}

The overall inappropriate use of topical steroids was $27.1 \%$, which was higher relative to the study conducted in India ${ }^{4}$ but relatively lower to the research conducted in Iraq..$^{5}$ This might be due to the practice amongst Ethiopian youngsters of using cosmetics just like their cultural practices of using butter, dermalar, etc., to enhance their appearance..$^{10}$ Moreover, around $67 \%$ of the respondents were found to be illiterate during the study. Thus, it might be one of the reasons making such a huge difference to that of India.

Surprisingly, $69.23 \%$ of the clients who used topical steroids developed at least one side effect. This being relatively higher to all the research conducted in other parts of the world. ${ }^{1-3}$ The reason being illiteracy $(67 \%)$, recommendations by family and friends (47\%), easy availability of the agents in every private pharmacy, drug stores, cosmetic centers and vendors $(31.7 \%)$. That is why the use of over the counter steroids in our country is so sky high.

Nearly $45.18 \%$ of the clients were using potent (more than class III) steroids in their daily lives, specially dermovate and betametason. This figure again was so higher relative to the research done in USA, India and Iraq. Nearly $75.98 \%$ of the patients were using topical steroids for the treatment of melasma and resacea. This might be as their living environment being the tropics and hence using topical steroids as sunscreen $(42.3 \%)$ as well as the treatment of acne.

\section{CONCLUSION}

Misuse of topical steroids was found to be very common owing to prescriptions by dermatologists, the major reason being recommendations by healthcare professionals, pharmacists, family and friends. Abuse of these steroids thus causing fungal infections leads to many other secondary complications. Hence, over the counter use of such steroids must be strictly banned and monitored by the Federal Ministry of Health, setting appropriate rules and regulations.

\section{RECOMMENDATION}

Topical steroids are agents that are prescribed for inflammatory disorders to abort the condition according to their potency and area of inflammation.

Thus, as a professional we recommend the federal, regional, zonal and woreda Ministry of Health to formulate appropriate rules and regulations to prevent the use of topical steroids at any degree/potency as over the counter pattern in Ethiopia.

\section{CONFLICTS OF INTEREST}

The authors declare that they have no conflicts of interest.

\section{REFERENCES}

1. Rathi S. Abuse of topical steroid as cosmetic cream: A social background of steroid dermatitis. Indian J Dermatol. 2006; 51: 154-155. doi: 10.4103/0019-5154.26949

2. Liu ZH, Du XH. Quality of life in patients with steroid dermatitis before and after treatment. J Eur Acad Dermatol Venereol. 2008; 22: 663-669. doi: 10.1111/j.1468-3083.2008.02639.x

3. Al-Dhalimi MA, Aljawahiri N. Misuse of topical corticosteroids: A clinical study from an Iraqi hospital. East Mediterr Health J. 2006; 12: 847-852. Web site. http://applications.emro. who.int/emhj/1206/12_6_2006_847_852.pdf. Accessed May 2, 2017.

4. Ference JD, Last AR. Choosing topical corticosteroids. Am Fam Physician. 2009; 79: 135-140. Web site. http://www.aafp. org/afp/2009/0115/p135.html. Accessed May 2, 2017.

5. Bhat YJ, Manzoor S, Qayoom S. Steroid-induced rosacea: A clinical study of 200 patients. Indian J Dermatol. 2011; 56: 3032. doi: 10.4103/0019-5154.77547

6. Ljubojeviae S, Basta JA, Lipozeneiae J. Steroid dermatitis resembling rosacea: Aetio-pathogenesis and treatment. $J$ Eur AcadDermatol Venerol. 2002; 16: 121-126. doi: 10.1046/j.14683083.2002.00388_2.x

7. Chen YY, Zirwas MJ. Steroid-induced rosacealike dermatitis: Case report and review of the literature. Cutis. 2009 83(4): 198-204. Web site. http://www.mdedge.com/cutis/article/67817/ contact-dermatitis/steroid-induced-rosacealike-dermatitis-casereport-and-review. Accessed May 2, 2017.

8. Vati RR, Ali F, Teuber S, Chanc C, Gershwin ME. Hypersenstivity reactions to corticosteroids. Clin Rev Allergy Immunol. 2014; 47: 26-37. doi: 10.1007/s12016-013-8365-z

9. Ljubojeviæ S, Basta-Juzbašviæ A, Lipozenèiæ J. Steroid dermatitis resembling rosacea: Aetiopathogenesis and treatment. J Eur Acad Dermatol Venereol. 2002; 16(2): 121-126. doi: 10.1046/j.1468-3083.2002.00388_2.x

10. Ethio cultural and educational sectors. 2003. Web site. http:// ethiopianculture.org/education.html. Accessed May 2, 2017. 